\title{
Vital rates of pink abalone Haliotis corrugata estimated from mark-recapture data to inform recovery
}

\author{
Cynthia A. Button ${ }^{1}$, Laura Rogers-Bennett ${ }^{2,3, *}$ \\ ${ }^{1}$ Scripps Institution of Oceanography, University of California San Diego, 9500 Gilman Drive, La Jolla, \\ California 92093, USA \\ ${ }^{2}$ Bodega Marine Laboratory, University of California Davis, PO Box 247, Bodega Bay, California 94923, USA \\ ${ }^{3}$ California Department of Fish and Game, Bodega Bay, California 94923, USA
}

\begin{abstract}
Pink abalone Haliotis corrugata have declined dramatically in southern California despite once being the most important species in the abalone fishery before its closure in 1997. We estimated vital rates using mark-recapture data of pink abalone from San Diego (2003-2007) and Santa Catalina Island (1970-1972), California, and juveniles reared in the laboratory in San Diego (2006-2007). We fit 7 growth functions to annual growth increment data to estimate age at maturity, time to reach the minimum legal size (MLS) in the historic fishery, and the number of reproductive years before reaching the MLS. We used demographic data to construct a growth transition probability matrix based on the best-fit (Richards) model. We estimated that pink abalone grow slowly ( $k=$ $\left.0.07 \mathrm{yr}^{-1}\right)$, reaching a maximum length of $200 \mathrm{~mm}$, and have high adult survivorship $\left(0.77 \mathrm{yr}^{-1}\right)$. We used non-lethal methods to estimate size at maturity, which was $99 \mathrm{~mm}$ for males and $103 \mathrm{~mm}$ for females ( 8.2 to $8.7 \mathrm{yr}$ ), with $19 \mathrm{yr}$ to reach fishery size. Survival rates in this population did not differ between years or genders, but severe cuts to the foot during handling did decrease survivorship. Despite low population densities, we show evidence of some juvenile recruitment to the region. The slow growth rates suggest that the populations within the southern California abalone fishery closure area could take $30 \mathrm{yr}$ to recover, provided there is successful reproduction and the high survival of adults continues without illegal fishing. Estimating vital rates and demographic characteristics using non-lethal methods provides critical information for investigating the dynamics of low-density populations.
\end{abstract}

KEY WORDS: Haliotis corrugata $\cdot$ Pink abalone $\cdot$ Demography $\cdot$ Restoration $\cdot$ Matrix model $\cdot$ Growth modeling $\cdot$ Survival rate $\cdot$ Maturity $\cdot$ Marine conservation

\section{INTRODUCTION}

Pink abalone Haliotis corrugata, once a dominant member of the subtidal community in southern California, are currently found in low abundances. Pink abalone are herbivores that feed primarily on kelp and other algae. Abalone growth and mortality rates may be influenced by oceanographic conditions that favor kelp growth such as cool La Niña conditions (Henderson et al. 1988, Vilchis et al. 2005). Reproduction may be negatively affected by low population numbers due to Allee effects. Fertilization success is diminished when spawning adults are further than 1 to $3 \mathrm{~m}$ apart, as is the case when population densities are low (Babcock \& Keesing 1999). Pink abalone recruitment had declined dramatically by the time the fishery closed in 1997. Juveniles have been rare inside Marine Protected Areas (MPAs) and elsewhere in southern California (Rogers-Bennett et al. 2002, Rogers-Bennett et al. 2004a), but recently there has been evidence of successful recruitment in the Point Loma kelp forest near San Diego, California (C. A. Button pers. obs.). 
Pink abalone are now listed as a species of concern by the National Oceanic and Atmospheric Association, yet little is known about their demographic parameters in southern California. Mark-recapture methods are particularly useful for determining growth and survivorship for populations in decline since these methods are non-lethal. Conservation efforts would be aided by determining demographic parameters for use in population models. For example, size-based population matrix models have been constructed for the endangered white abalone, where the largest size class had the most influence on population growth (Rogers-Bennett \& Leaf 2006). These results suggest that conservation efforts which focus on protecting, aggregating, and stocking large abalone may be more beneficial than focusing on juveniles; similar findings have been reported for other long-lived species such as sea turtles (Crouse et al. 1987).

The goal of the present study was to estimate vital rates (e.g. growth, survival, and size at maturity) for pink abalone populations in southern California using non-lethal methods. We used 7 functions to estimate growth using mark-recapture data, plotting growth increment with size. Using the best-fit growth model, we calculated the average age at maturity, the time to reach the minimum legal size (MLS) in the historic fishery, and the reproductive period prior to reaching this size. We also estimated the size at maturity for this species to design a growth transition probability matrix. Survival rates were estimated from markrecapture data and compared across years, genders, and different levels of damage during handling. We discuss the implication of these growth and survival rate estimates for population recovery.

\section{MATERIALS AND METHODS}

Study area. Pink abalone Haliotis corrugata were marked inside the Point Loma kelp forest near San Diego, California. The Point Loma kelp forest $\left(32^{\circ} 42^{\prime} \mathrm{N}, 117^{\circ} 16^{\prime} \mathrm{W}\right)$ is large, extending $\sim 10 \mathrm{~km}$ along the coast (Dayton et al. 1992) (Fig. 1). Within the central part of the kelp forest, we demarcated a 9 ha area $(300 \times 300 \mathrm{~m})$, which ranged in depth between 12 and $15 \mathrm{~m}$ and contained substantial pink abalone habitat. Tag locations were obtained by a random number generation of latitudes and longitudes within the 9 ha area. The study area is characterized by a low-relief sandstone and mudstone substrate with scattered boulders and extensive ledge systems and is dominated by giant kelp Macrocystis pyrifera, with holdfasts often measuring over $1 \mathrm{~m}$ in diameter. Clearings in the giant kelp are dominated by understory kelp species (Laminaria, Pterygophora, and Eisenia).
Sampling methods. We tagged 365 pink abalone during 6 survey periods from December 2003 to October 2006. The length of each survey period ranged from 1 to $176 \mathrm{~d}(\mu=84 \mathrm{~d} ; \sigma=33.4 \mathrm{~d})$. Abalone were collected and brought up to the boat for tagging. We recorded individual statistics including the shell length (measured as the longest length across the shell, hereafter referred to as size) and gender of each tagged individual. We also qualitatively assessed the level of damage to the foot of the abalone that may have unintentionally occurred during the collection process as one of 5 categories: no damage $(\mathrm{n}=240)$, light cut (to the foot) $(\mathrm{n}=65)$, moderate cut $(\mathrm{n}=26)$, severe cut $(\mathrm{n}=$ $28)$, and other $(n=6)$. Although dimensions of the damaged area were not measured, the differences among these categories were clear and abalone could quickly be assigned to a category without doubt. A light cut was typically $\sim 1 \mathrm{~mm}$ deep and resulted from the iron barely grazing the foot. Moderate cuts were deeper, enough to produce a small flap of the foot, approximately 1 to $3 \mathrm{~mm}$ deep. Severe cuts to the foot were typically much greater than $3 \mathrm{~mm}$ deep but did not penetrate into the body cavity.

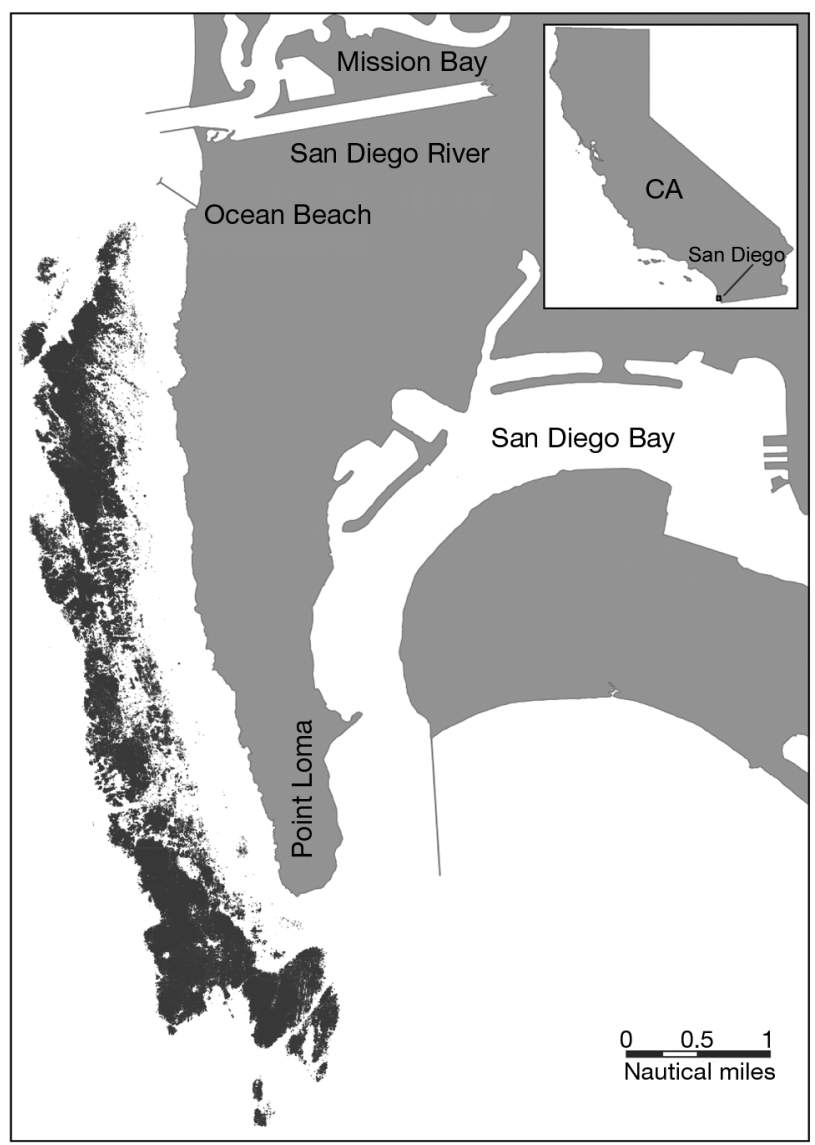

Fig. 1. Map of Point Loma kelp forest (offshore dark gray shaded area) near San Diego, California. Inset map is of California 


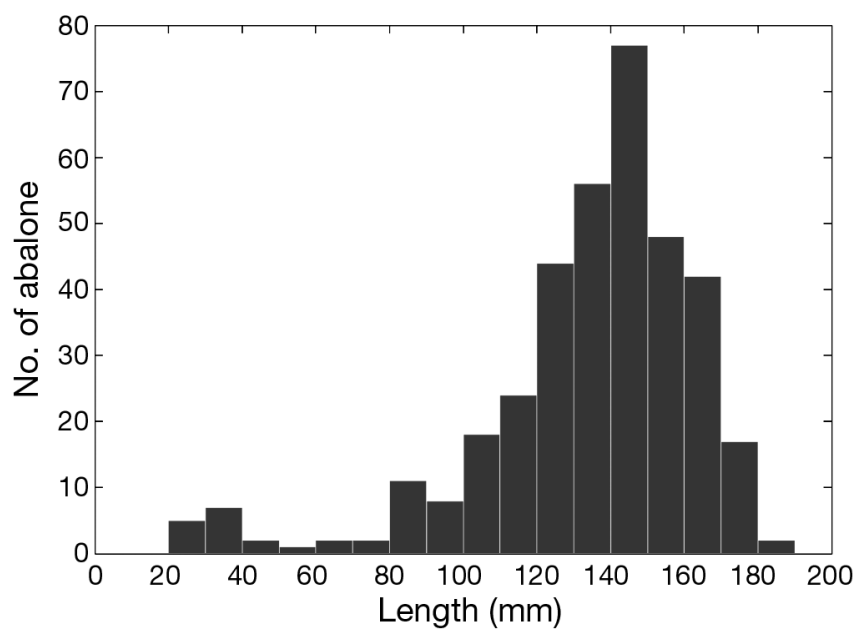

Fig. 2. Haliotis corrugata. Size-frequency distribution of tagged pink abalone $(2003-2006 ; \mathrm{n}=365)$

The tagged abalone ranged in initial size between 23 and $184 \mathrm{~mm}$ (Fig. 2). Abalone were marked with numbered stainless steel washer tags wired through 2 adjacent respiratory holes in the shell with stainless steel wire (Haaker et al. 1998). After the tagging process, abalone were returned to suitable habitat at the same site by scuba divers.

Subsequent visits to the tagging sites were conducted to obtain growth and survival estimates. Because the pink abalone at this location were relatively sedentary, we were able to re-encounter tagged individuals by revisiting the original tagging locations each year. The timing of these visits was opportunistic, between April and October of each year, so that the intervals between encounters were not always equal to $1 \mathrm{yr}$. We recorded the date, tag number, and length of the individual pink abalone to the nearest millimeter. During the final years of the study (2006 and 2007), we removed the abalone from the substrate before measuring them while under water. All of the abalone measured in this way were replaced on the exact location from which we took them. We measured the size 5 or more times in order to estimate the measurement error.

Growth estimation. In order to estimate the sizespecific growth rate of individuals in this population, all growth increment data were standardized to annual increments by $\Delta L_{365}=\Delta L_{t}(365 / t)$, where $\Delta L_{t}$ is the measurement difference between the 2 survey dates and $t$ is the time at large in number of days. Only individuals with $t>243 \mathrm{~d}$ were included in the growth study in order to avoid extrapolating the annual growth rates from shorter time periods. We also excluded abalone with $t>487 \mathrm{~d}$ so that annual growth increments were not underestimated based on averaging over many years. In cases of multiple encounters, individual growth rates were calculated for the period at large closest to $1 \mathrm{yr}$. The average time interval was $1.0 \mathrm{yr}$ $(\sigma=0.13 \mathrm{yr})$.

Growth increments for small individuals (<79 mm) were unavailable from the mark-recapture data because none of the 17 individuals that we tagged were re-encountered. These smaller individuals occupy very cryptic habitat (e.g. under boulders and in small crevices) and are thought to be much more mobile than the adults. They may have moved out of the tag area or succumbed to predation. Although these smaller size classes are uncommon at present, future tagging efforts will need to tag many more juveniles to increase the chance of re-encounters.

To supplement the growth data, we measured 140 juvenile pink abalone reared in the Southwest Fisheries Science Center facility from Point Loma pink abalone broodstock. These juveniles were maintained in ambient water temperature and fed an initial diet of diatoms cultured naturally from Point Loma algae (a mixture of fleshy red algae and kelp species). We also included juvenile pink abalone growth data reported by Tutschulte (1976) for 54 additional abalone ranging in initial size between 14 and $79 \mathrm{~mm}$. In Tutschulte's study, 35 of these abalone were maintained in net cages at $9 \mathrm{~m}$ depth. A mixture of red algae and kelp species were placed in the cages periodically to provide food. A further 15 abalone were marked and released into the wild and 4 individuals were released on tiles at $9 \mathrm{~m}$ depth; all these abalone were recaptured the following year. In all cases, tags were attached with wire through the respiratory holes and a small notch was made in the abalone shell that would serve as a reference point for measuring the growth increment the following year.

We investigated the fit of 7 growth functionsGaussian, Tanaka, logistic dose-response, Ricker, Gompertz, Richards, and the von Bertalanffy growth curve - to the annual growth increment data $(\Delta L)$ versus the initial size $\left(L_{0}\right)$ of all available data (RogersBennett et al. 2007). The relative fit of these models to the pink abalone growth data was determined by ranking the Akaike Information Criterion (AIC) values (Akaike 1974). We also examined $R^{2}$ values, the sum of the squared residuals (SSR), and the Bayesian Information Criterion (BIC) as alternative methods for determining the best-fit model. The most parsimonious model was chosen for use in estimating the growth transition probabilities, which describes the probability that an individual will either remain in the same size class or grow into the next within $1 \mathrm{yr}$. We calculated the mean and $95 \%$ confidence intervals of the transition probabilities based on the model parameter estimates (Rogers-Bennett \& Rogers 2006). The transition probabilities were calculated for a $5 \times 5$ size-based 
matrix. The 5 stages in the model are defined by $25 \mathrm{~mm}$ size classes: (1) small juveniles (25-50 mm), (2) intermediate-sized juveniles (50-75 mm), (3) subadults that are transitioning from an immature to a mature state (75-100 mm), (4) intermediate-sized adults (100$125 \mathrm{~mm}$ ), and (5) large adults (>125 mm).

Size at maturity. Size at maturity is an important demographic characteristic to determine for a population because of its influence on the net reproductive rate of individuals. An effective method for determining the size at maturity is to examine the maturity of egg samples taken from histological sections of the gonad from multiple individuals across a broad range of sizes (Rogers-Bennett et al. 2004b). This method requires sacrificing individuals but allows for differentiation of immature, mature, and necrotic (abnormal or senescent) eggs. Due to the low abundance of the local pink abalone population, the options for assessing the size at maturity were limited to non-lethal methods. We used the size at which gender determination was possible as a proxy for the size at maturity for the Point Loma pink abalone population.

The standard method of determining the gender of live abalone is to inspect the color of the gonad by pulling the foot away from the shell on the right posterior side of the abalone. When the abalone is gravid with gametes (i.e. the gonad is swollen), this method is effective; however, less gravid males may be reported as females because of the similarity in gonad color. When the gender determination based on visual inspection of the gonad color was inconclusive, we sampled the gonad with a 16-gauge syringe and examined the contents of the sample for either eggs or sperm. If the sample contained neither gamete type, we recorded that individual as immature.

Before applying the syringe sampling method to wild abalone, we used this method on red abalone Haliotis rufescens in the laboratory to determine if it was nonlethal. On February 25, 2005, we tagged 27 red abalone housed in Bodega Marine Laboratories at the University of California, Davis, using the tagging methods described above. We measured the lengths and weights of each abalone and determined the gender based on visual inspection of gonad color. We randomly chose 9 of the abalone to sample the gonad with a 25-gauge syringe, 9 to sample with a 16-gauge syringe, and the remaining 9 were not sampled with a syringe. The genders of the 18 sampled abalone were then determined by inspecting the samples for gametes. All of the abalone were returned to a flow-through seawater tank in ambient water temperature for $75 \mathrm{~d}$. No mortality resulted by the end of this period. At the end of the experiment, all 27 abalone were dissected to assess the accuracy of the syringe method for determining gender. Only $64 \%$ of the genders determined by visual inspection of gonad color were consistent with the genders determined by dissection whereas $89 \%$ of those sampled with a 25 -gauge syringe and $100 \%$ of those sampled with a 16-gauge syringe agreed with the sex determined by lethal gonad dissection.

In order to estimate the relationship between size and maturity in the Point Loma pink abalone, we determined the genders of 160 abalone in 2006 and 2007. We fit a generalized linear model with a binomial distribution to the data, where a positive gender identification was given a value of 1 and an immature individual was designated by 0 . The size at which $50 \%$ of the abalone were estimated to be mature was used as the size at maturity for this population. The equation that was fit to the data was:

$$
P\left(L_{i}\right)=\frac{\mathrm{e}^{\left(\beta_{0}+\beta_{1} L_{i}\right)}}{1+\mathrm{e}^{\left(\beta_{0}+\beta_{1} L_{i}\right)}}
$$

where $P\left(L_{i}\right)$ is the probability of successful gender determination, $L_{i}$ is the length of the abalone, and $\beta_{0}$ and $\beta_{1}$ are parameter estimates of the linear predictor.

Age at size. The relationship between length and age was determined by iteratively solving the fitted growth functions, starting at a small initial size $(0.01 \mathrm{~mm})$. Using these size-at-age curves, we estimated the average age at maturity and the average time to reach the MLS in the historic recreational $\left(\mathrm{MLS}_{\mathrm{R}}=153 \mathrm{~mm}\right)$ and commercial fisheries $\left(\mathrm{MLS}_{\mathrm{C}}=\right.$ $159 \mathrm{~mm}$ ). We tested the sensitivity of these estimates to changes in the model parameters by varying the parameters by $\pm 10 \%$.

Survival estimation. Individual survival rates of tagged abalone were estimated with the CormackJolly-Seber (CJS) approach available in Program MARK (http://warnercnr.colostate.edu/ gwhite/mark/ mark.htm), a free software program designed for analyzing mark-recapture data (White \& Burnham 1999). The CJS approach allows for the simultaneous estimation of survival $(\varphi)$ and recapture $(p)$ probabilities in the population based on individual encounter histories. We used the CJS method (Cormack 1964, Jolly 1965, Seber 1965) to fit a series of a priori $\varphi$ and $p$ probability models which tested the time dependence (i.e. year-to-year changes) of each variable. Individual encounter histories were also categorized to enable estimation of how gender and the degree of damage to the foot affected survival rates. To determine the effect of damage incurred incidentally during the tagging process on the subsequent survival of individuals, we divided the encounter histories $(\mathrm{n}=342)$ into 4 groups, excluding individuals recorded with 'other' damage. Because we did not re-encounter any tagged individuals smaller than $79 \mathrm{~mm}$ throughout the study, we also excluded these smaller individuals from the analysis 
$(\mathrm{n}=17)$. In a separate analysis, we estimated the survival of males $(n=105)$ and females $(n=114)$. We included in this analysis only those individuals for which we had positively determined their genders (e.g. sexually mature individuals that were reproductive at the time of gender determination). A third analysis was conducted to estimate the overall average survival rate for the population, which treated all groups as equal $(\mathrm{n}=314)$. For this analysis, any treatment group previously found to differ in its survival rate (i.e. severely cut individuals) was excluded from the analysis. We also excluded individuals smaller than $79 \mathrm{~mm}$ and those with 'other' damage.

Goodness of fit (GOF) tests for the most general, fully time-dependent model $\left(\varphi_{t} p_{t}\right)$ in the candidate model set (Test2 and Test3 in program RELEASE, accessed through Program MARK) were performed to determine if the basic assumptions of the mark-recapture methods had been met. The most critical of these assumptions are that all individuals have equal catchability (Test2) and survival (Test3) (Lebreton et al. 1992, Krebs 1999). Violations of these assumptions may result in overdispersed data for the model. In such cases, a parameter describing the overall dispersion in the data, $\hat{\mathrm{c}}$, was used to adjust the rankings and relative weights of the candidate models. The $\hat{c}$ parameter was estimated by the median- $\hat{c}$ simulation method in Program MARK. The quasi-AIC ${ }_{\mathrm{c}}\left(\mathrm{QAIC}_{\mathrm{c}}\right)$ value is the model AIC value adjusted by the value of $\hat{c}$ to accommodate overdispersion in the data. For all analyses, we report the survival and detectability estimates of the most parsimonious model because the difference in $\mathrm{QAIC}_{\mathrm{C}}$ values were greater than 2.0 units.

\section{RESULTS}

\section{Growth estimation}

Annual growth increments were calculated for 72 pink abalone Haliotis corrugata from Point Loma, ranging in initial size from 79 to $178 \mathrm{~mm}(\mu=143.0 \mathrm{~mm}$; $\sigma=18.4 \mathrm{~mm}$ ). The measurement error (standard deviation of 5 to 10 measurements) associated with re-measuring individuals while under water ranged between 0.0 and $1.4 \mathrm{~mm}(\mu=0.4 \mathrm{~mm} ; \sigma=0.3 \mathrm{~mm})$. The measurement error for growth increments was $0.6 \mathrm{~mm}$. The average annual growth increment was $2.0 \mathrm{~mm} \mathrm{yr}^{-1}(\sigma=$ $6.3 \mathrm{~mm} \mathrm{yr}^{-1}$ ). Negative growth was observed in 21 individuals (131 to $175 \mathrm{~mm}$ length). We treated these observations of negative growth as valid because individuals with multiple measurements through time corroborated the finding. None of the 7 candidate growth models allow negative growth of large (old) individuals. Therefore, we excluded the negative val- ues in the primary analysis, only fitting the portion of the curve in which individuals were growing (i.e. growth prior to shrinkage due to old age). To determine the influence of negative growth on the results, we conducted a second analysis which included all available data.

A total of 140 abalone spawned on August 11, 2006, and reared under laboratory conditions were measured on November 16, 2007 (467 d old). The average annual growth increment estimated for these youngof-the-year abalone was $22 \mathrm{~mm}(\sigma=2.3 \mathrm{~mm})$. Annual growth increments of intermediate-sized individuals, from Tutschulte (1976) and Tutschulte \& Connell (1988), were slower and highly variable $(\mu=13.2 \mathrm{~mm}$; $\sigma=6.1 \mathrm{~mm})$.

The Richards function was the best-fit model for the growth increment data according to all of the model ranking methods examined (Tables 1 \& 2). The Richards function accommodated the concavity of the growth curve in the intermediate size range (Fig. 3). Neither the Ricker nor the Gompertz function fitted the

Table 1. Goodness-of-fit results for the 7 growth functions used to model pink abalone size-specific growth. AIC: Akaike Information Criterion; BIC: Bayesian Information Criterion; SSR: Sum of Squared Residuals; R ${ }^{2}$ : R-squared value

\begin{tabular}{|lrrrr|}
\hline Model & AIC & BIC & SSR & $\mathrm{R}^{2}$ \\
\hline Richards & 682.7 & 693.2 & 3878 & 0.76 \\
Tanaka & 692.0 & 702.5 & 4029 & 0.75 \\
Logistic dose-response & 695.6 & 706.1 & 4089 & 0.74 \\
Gaussian & 696.7 & 707.2 & 4107 & 0.74 \\
von Bertalanffy & 712.6 & 719.6 & 4418 & 0.72 \\
Gompertz & 1375.0 & 1385.5 & 65449 & -3.12 \\
Ricker & 1382.8 & 1389.8 & 68111 & -3.29 \\
\hline
\end{tabular}

Table 2. Parameter estimates and 95\% confidences intervals (L95\%: lower 95\% CI; U95\%: upper 95\% CI) for the 5 best-fit growth functions. Where no unit is shown, the parameter is dimensionless

\begin{tabular}{|c|c|c|c|c|c|}
\hline Model & Parameter & Units & Estimate & L95\% & U95\% \\
\hline Richards & $\begin{array}{c}k \\
L_{\infty} \\
n\end{array}$ & $\begin{array}{l}\mathrm{yr}^{-1} \\
\mathrm{~mm} \\
-\end{array}$ & $\begin{array}{c}0.07 \\
200.1 \\
-0.82\end{array}$ & $\begin{array}{c}0.04 \\
169.4 \\
-0.88\end{array}$ & $\begin{array}{c}0.09 \\
230.7 \\
-0.76\end{array}$ \\
\hline Tanaka & $\begin{array}{l}a \\
d \\
f\end{array}$ & $\begin{array}{l}- \\
- \\
-\end{array}$ & $\begin{array}{c}-0.008 \\
667.8 \\
0.0001\end{array}$ & $\begin{array}{c}-0.026 \\
262.9 \\
0.0000\end{array}$ & $\begin{array}{c}0.010 \\
1072.7 \\
0.0002\end{array}$ \\
\hline $\begin{array}{l}\text { Logistic dose- } \\
\text { response }\end{array}$ & $\begin{array}{l}a \\
b \\
c\end{array}$ & $\begin{array}{l}\mathrm{mm} \\
\mathrm{yr}^{-1} \\
\mathrm{~mm}\end{array}$ & $\begin{array}{c}21.5 \\
46.7 \\
1.1\end{array}$ & $\begin{array}{c}20.8 \\
38.3 \\
0.9\end{array}$ & $\begin{array}{c}22.2 \\
55.1 \\
1.4\end{array}$ \\
\hline Gaussian & $\begin{array}{c}A \\
m \\
S\end{array}$ & $\begin{array}{c}\mathrm{mm} \\
\mathrm{mm} \\
-\end{array}$ & $\begin{array}{c}661.4 \\
-618.8 \\
235.9\end{array}$ & $\begin{array}{c}-9096.2 \\
-3084.7 \\
-199.4\end{array}$ & $\begin{array}{c}10419.1 \\
1847.2 \\
671.1\end{array}$ \\
\hline von Bertalanff & ffy $\begin{array}{l}k \\
L_{\infty}\end{array}$ & $\begin{array}{l}\mathrm{yr}^{-1} \\
\mathrm{~mm}\end{array}$ & $\begin{array}{c}0.13 \\
168.5\end{array}$ & $\begin{array}{c}0.12 \\
157.3\end{array}$ & $\begin{array}{c}0.14 \\
179.7\end{array}$ \\
\hline
\end{tabular}




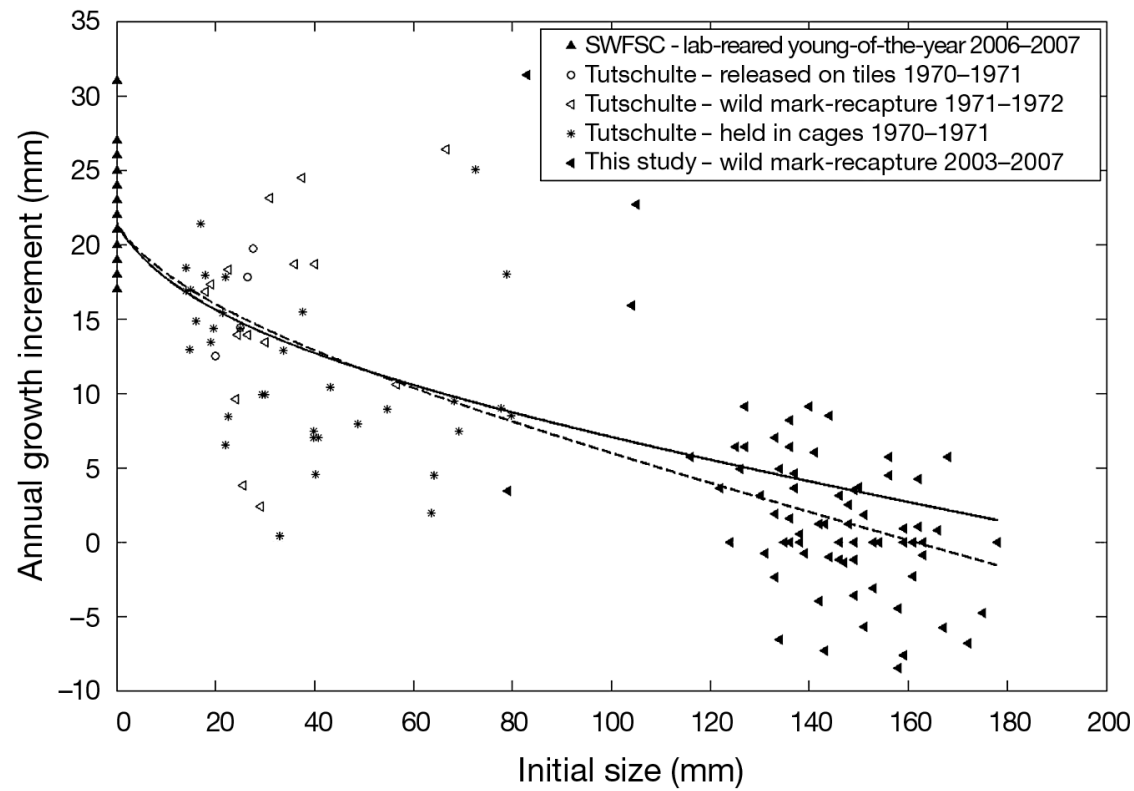

Fig. 3. Haliotis corrugata. Richards function fit to pink abalone growth data. Solid line is the fit to positive growth data only $(n=245)$. Dashed line is the fit to all data, including negative growth $(\mathrm{n}=266)$. SWFSC: abalone reared in the Southwest Fisheries Science Center; Tutschulte: growth data reported by Tutschulte (1976) individuals, $89 \%$ were mature, including 64 male, 79 female, and 17 immature abalone. Eight of the abalone were smaller than $100 \mathrm{~mm}$. The smallest male abalone successfully identified was $88 \mathrm{~mm}$ and the smallest female was $94 \mathrm{~mm}$. The largest sampled abalone with insufficient gametes for gender determination was $167 \mathrm{~mm}$. This individual was sampled on June 18, 2007, which is the middle of the spawning period for pink abalone (April to November). The parameters of the generalized linear model fit the data well (females: $\beta_{0}=-5.2[\mathrm{SE}=1.8 ; \mathrm{p}=$ $0.0032], \beta_{1}=0.05 \quad[\mathrm{SE}=0.01 ; \mathrm{p}=$ $0.0001]$; males: $\beta_{0}=-4.2[\mathrm{SE}=1.5 ; \mathrm{p}=$ $0.0064], \quad \beta_{1}=0.04 \quad[\mathrm{SE}=0.01 ; \mathrm{p}=$ $0.0003])$. The size at which the gender of the abalone could be determined $50 \%$ of the time was very similar for males $(99 \mathrm{~mm})$ and females (103 mm) (Fig. 4). data well. These functions failed by underestimating growth rates at small initial sizes. Exclusion of negative growth values had very little impact on the fit of the model to the small and intermediate size classes. Estimates of the Richards parameters $k$ (growth constant) and $n$ (shape parameter) changed very little, but $L_{\infty}$ (maximum shell lengths in population) decreased from $200 \mathrm{~mm}$ (excluding negative values) to $161 \mathrm{~mm}$ (including negative values). This larger estimate of $L_{\infty}$ agrees with the maximum known length of the species ( $200 \mathrm{~mm})$. Growth transition probabilities based on the Richards equation fit to the data are reported in Table 3.

\section{Size at maturity}

The abalone used to determine size at maturity ranged in size between 36 and $177 \mathrm{~mm}$. Of these

\section{Age at size}

The estimated age at maturity based on the Richards function fit to the data was $8.2 \mathrm{yr}$ for males and $8.7 \mathrm{yr}$ for females (Fig. 5). Sensitivities in the results ranged from 7.8 to $8.5 \mathrm{yr}$ for males and from 8.3 to $9.1 \mathrm{yr}$ for females. The estimated time-to-fishery for the recreational fishery (TTF-MLS ${ }_{\mathrm{R}}$ ) was $18.9 \mathrm{yr}$. Sensitivities in the results ranged from 18.0 to $20.0 \mathrm{yr}$. The estimated time-to-fishery for the commercial fishery (TTF-MLS $\mathrm{S}_{\mathrm{C}}$ ) was 20.9 yr. Sensitivities ranged from 19.9 to $22.0 \mathrm{yr}$. The sensitivity to parameter estimates increased as the size of interest increased, such that the greatest sensitivities were observed in the time to reach the $\mathrm{MLS}_{\mathrm{C}}$. The estimated time between reaching maturity and entering the historic recreational fishery was approximately 10 yr. The estimated time between entering the historic recreational fishery and entering the historic

Table 3. Growth transition probabilities estimated from the best-fit model (Richards function), excluding negative growth values. Probabilities are given as mean (lower $95 \% \mathrm{CI}_{\text {; }}$ upper $95 \% \mathrm{CI}$ )

\begin{tabular}{|lccccc|}
\hline Size class $(\mathrm{mm})$ & $25-49.9$ & $50-74.9$ & $75-99.9$ & $100-124.9$ & $\geq 125$ \\
\hline $25-49.9$ & $0.48(0.76 ; 0.00)$ & $0.52(0.24 ; 1.00)$ & 0 & 0 & 0 \\
$50-74.9$ & 0 & $0.60(0.82 ; 0.23)$ & $0.40(0.18 ; 0.77)$ & 0 & 0 \\
$75-99.9$ & 0 & 0 & $0.69(0.87 ; 0.40)$ & $0.31(0.13 ; 0.60)$ & 0 \\
$100-124.9$ & 0 & 0 & 0 & $0.78(0.92 ; 0.54)$ & $0.22(0.08 ; 0.46)$ \\
$\geq 125$ & 0 & 0 & 0 & 0 & 1 \\
\hline
\end{tabular}




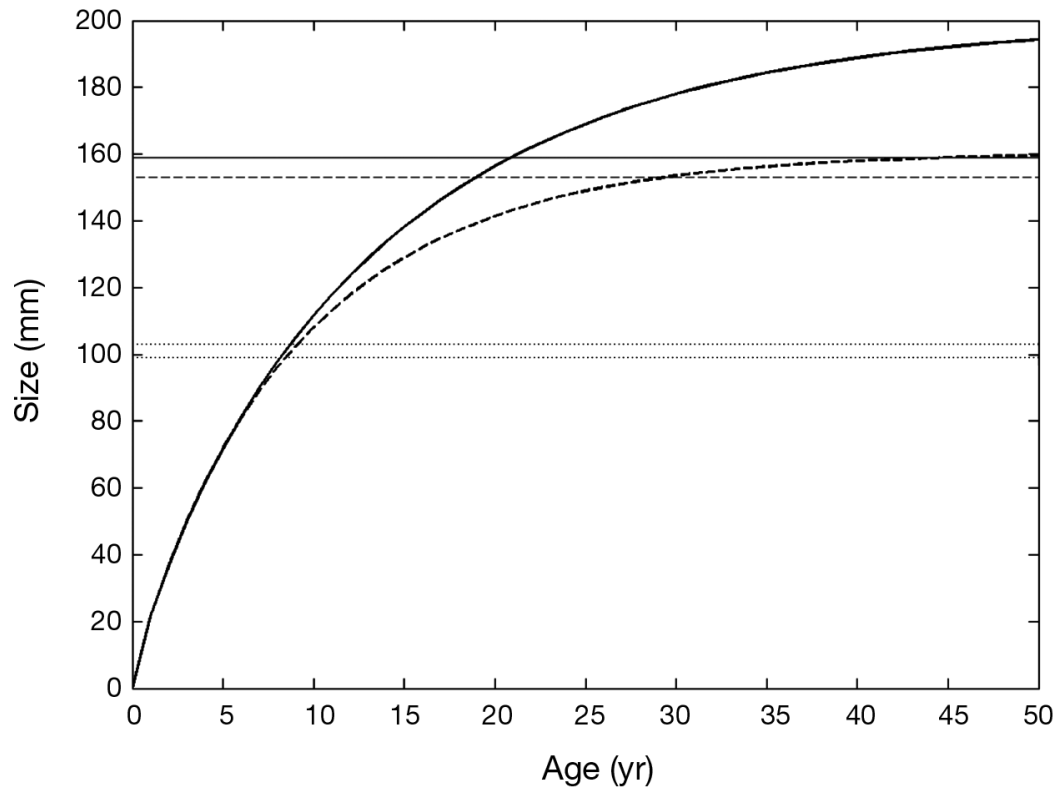

Fig. 4. Haliotis corrugata. Average size at age calculated based on the fitted Richards growth model, excluding negative growth (solid line), and including all data (dashed line). Horizontal lines indicate the historic minimum legal size for the commercial fishery (solid), and for the recreational fishery (dashed), and the estimated average sizes at maturity (dotted lines: upper, females; lower, males)

commercial fishery was 2 yr. The inclusion of negative values in the secondary analysis did not affect estimates of the age at maturity, but the time-to-fishery was very sensitive to the lowered estimate of $L_{\infty}$ (Fig. 5). rank the models (Table 4). In all 3 analyses (damage-specific, genderspecific, and total average survival), the difference in the QAIC values between the 2 best-fit models was greater than 2.0 units, indicating that the 2 models were not equivalent.

Survival probabilities were similar for abalone with no damage to moderate damage (no damage: $0.74 \pm 0.05$ $\mathrm{SE}$; light cut: $0.84 \pm 0.07 \mathrm{SE}$; moderate cut: $0.86 \pm 0.09 \mathrm{SE}$ ), but were much reduced for abalone with severe damage to the foot $(0.52 \pm 0.11 \mathrm{SE})$. The $95 \%$ confidence intervals around the average estimates revealed overlap in the range of estimated survival rates across groups. Survival probabilities were also the same for females and males, and did not change through time $(0.73 \pm 0.05 \mathrm{SE})$. Overall survival probability estimates for individuals greater than $78 \mathrm{~mm}$ were similar to those obtained using the gender analysis $(0.77 \pm 0.05 \mathrm{SE})$.

All of the best-fit candidate models included time as a factor influencing the recapture probabilities. The recapture probability increased as the length of the survey period increased. The lowest recapture probability $(0.01)$ occurred during the 3rd

\section{Survival estimation}

The range of initial sizes of tagged pink abalone used in the survival analyses was 79 to $187 \mathrm{~mm}$, although the number of individuals included in each subset of the analyses differed (Table 4). Goodness of fit tests from Program RELEASE indicated that the model assumptions were appropriate for the data included in the damage level and gender analyses, with non-significant p-values for Test2, Test3, and the combined tests. The p-values for Test 2 and the combined tests for the analysis using all of the individuals were significant (Test2: $p=0.001$; combined: $p=0.008$ ), indicating that not all of the individuals in the study had equal recapture probabilities. The test of binomial dispersion in the data (median $\hat{c}$ ) showed some overdispersion, so that QAIC values, weights, and deviances were used to

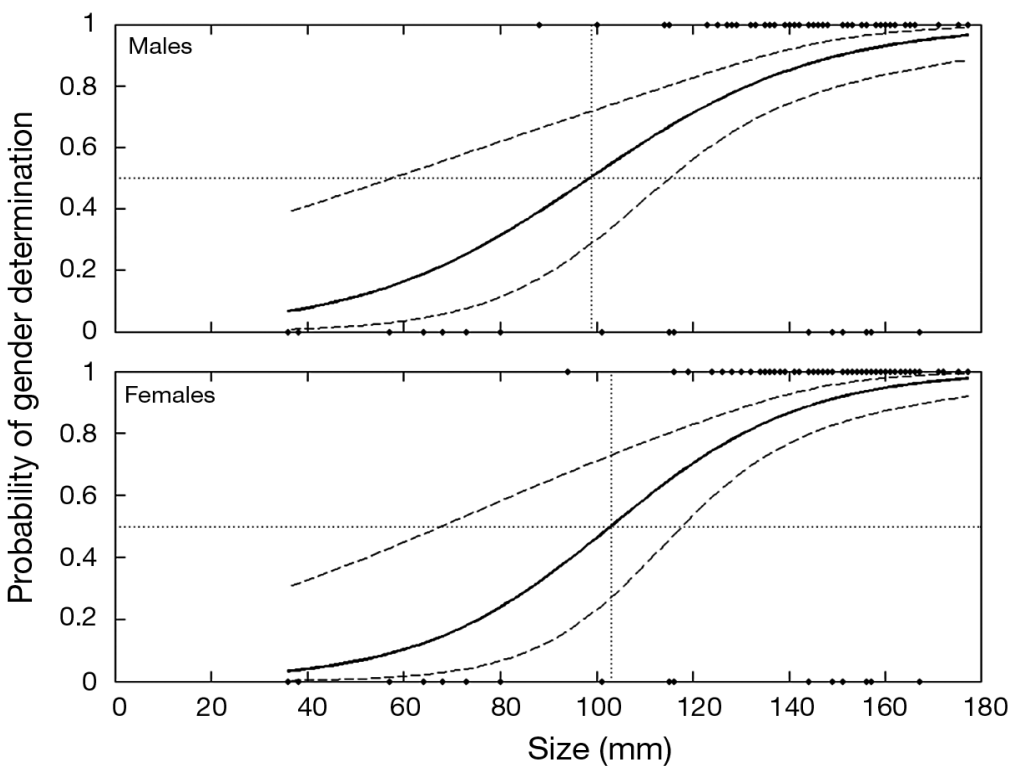

Fig. 5. Haliotis corrugata. Relationship between length and gender determination. Black diamonds (upper and lower margins of panels) indicate binomial data for individuals $(0=$ gender unknown; $1=$ gender known). Solid line represents the fit of a generalized linear model to the data. $95 \%$ confidence intervals shown by dashed lines. Vertical dotted lines reference the estimated size at $50 \%$ maturity 
Table 4. Summary of the best-fit survival and detectability models used for the simultaneous estimation of survival ( $\varphi$ ) and recapture $(p)$ probabilities. A subscript of $d$ means that damage was a factor in the model, $g$ refers to gender, $t$ refers to time (yr), and a ' ' indicates that the survival or recapture probability was constant across years and/or groups

\begin{tabular}{|c|c|c|c|c|c|c|c|}
\hline Analysis & No. of abalone & Models & No. of parameters & QAIC $_{\mathrm{c}}$ & $\Delta \mathrm{QAIC}_{\mathrm{c}}$ & Qdeviance & Median Ĉ \\
\hline \multirow[t]{3}{*}{ Damage } & 342 & $\varphi_{d} p_{t}$ & 9 & 985.76 & 0.00 & 131.45 & 1.10 \\
\hline & & $\varphi . p_{t}$ & 6 & 988.44 & 2.68 & 140.30 & \\
\hline & & $\varphi_{t} p_{t}$ & 9 & 990.75 & 4.98 & 136.43 & \\
\hline \multirow[t]{3}{*}{ Gender } & 219 & $\varphi . p_{t}$ & 6 & 521.62 & 0.00 & 38.92 & 1.21 \\
\hline & & $\varphi_{g} p_{t}$ & 7 & 523.69 & 2.07 & 38.90 & \\
\hline & & $\varphi_{t} p_{t}$ & 9 & 526.68 & 5.06 & 37.69 & \\
\hline \multirow[t]{2}{*}{ All } & 314 & $\varphi \cdot p_{t}$ & 6 & 531.30 & 0.00 & 43.36 & 1.95 \\
\hline & & $\varphi_{t} p_{t}$ & 9 & 535.93 & 4.63 & 41.82 & \\
\hline
\end{tabular}

survey period in the winter of 2005 (survey period $=9$ d). The highest recapture probability occurred during the 2nd survey period in the summer of 2004 (survey period $=176 \mathrm{~d})$. A regression of the relationship between survey period length ( $x$-axis) and recapture probability ( $y$-axis) yielded a positive linear function of $y=0.0033 x+0.0798\left(\mathrm{R}^{2}=0.8621\right)$.

\section{DISCUSSION}

Pink abalone in Haliotis corrugata southern California are characterized by slow growth and high survivorship of adult individuals. Annual growth increments were largest for the smallest individuals and growth rates decreased as the size of the abalone increased. Some large individuals exhibited negative growth (shrinking). The size at maturity was similar between males $(99 \mathrm{~mm})$ and females $(103 \mathrm{~mm})$. The estimated age at maturity was 8 to 9 yr. Pink abalone require $20 \mathrm{yr}$ of growth prior to entering the fishery at the former MLSc. Estimates of survival rates in this population did not differ between survey years, or between genders, but severe cuts to the foot of the abalone did decrease survival. The estimated vital rates from this study were used to develop a stagebased growth transition probability matrix which provides the foundation for a matrix population model and population viability analysis (Caswell 2001, Morris \& Doak 2002).

\section{Growth estimation}

The 7 candidate growth models chosen for this study represent a broad range of possible curves, from linear to sigmoidal, with few estimated parameters (2 to 3 ). All these models have been used to investigate growth rates of benthic invertebrates in prior studies. The von Bertalanffy, Gompertz, and Richards functions belong to a family of functions differentiated by the value of the exponential parameter $(n)$. The logistic doseresponse, Gaussian, Ricker, and Tanaka functions allow greater flexibility in fitting the small to mid-sized individual growth rates, but do not allow negative growth. Of the 7 candidate models, the Richards function provided by far the best fit to the data, with an AIC value at least 9 points lower than the second best-fit model (Table 1).

One feature of all the models is that they assume that individuals will eventually reach an asymptotic size over time, and then maintain that size until death. This assumption is at odds with the observation of negative growth for large individuals. The inclusion of negative growth could lead to an underestimate of the maximum size attained in the population and an overestimate of the growth rate constant $(k)$. Estimates of age at maturity based on the Richards family of equations depend primarily on the value of the growth rate constant $k$, because the size at maturity is well below the estimated asymptotic size. The results for $k$ were robust to the inclusion of the negative growth data. However, the estimated age of recruitment to the fishery is sensitive to the choice of $L_{\infty}$, which decreased from 200 to $161 \mathrm{~mm}$ when negative growth data were included in the analysis. We caution that as the estimate of $L_{\infty}$ approaches the MLS for the fishery (in this case $\mathrm{MLS}_{\mathrm{R}}=153 \mathrm{~mm}$ ), as is the case with an $L_{\infty}$ of $161 \mathrm{~mm}$, the estimated age of recruitment to the fishery becomes less certain (Fig. 5).

No easy solution exists to overcome this issue with estimates of $L_{\infty}$ for populations with negative growth rates of older individuals. Some authors suggest adopting a value of $L_{\infty}$ equal to the maximum observed size in the population, but this practice might bias the estimate of $k$, and may result in poor fits to the growth increment data. Using longitudinal (i.e. repeated measures) data to fit a mixed-effects model which allows negative growth in older individuals may alleviate this bias, but these models are complex and the data 
needed require a longer-term investment in monitoring a population. In the absence of longitudinal data, our approach was to exclude the negative values in the cross-sectional analysis of the data so that the data conform to the assumption of asymptotic size. We also translated the fitted curve into a growth transition matrix, where the lower limit of the largest size class is well below the sizes at which negative growth occurred, so that the transition probability is less affected. We emphasize that negative growth rates of large individuals could be very important to the dynamics of the population, so that future monitoring programs could focus on obtaining long-term longitudinal data where possible. We also encourage collecting multiple measures of size (i.e. width, and height as well as length) because the reduction in length of older individuals may be accommodated by an increase in other dimensions.

The predicted growth rates for individuals using the southern California datasets were slower than those reported for populations in Baja California, Mexico (Doi et al. 1977, Marín Aceves 1981, Guzmán del Próo 1992, Shepherd \& Avalos-Borja 1997) but were similar to those reported for Santa Catalina Island, California, based on analyses of size-frequency distributions in 1971 and 1972 (Tutschulte \& Connell 1988). Depending on the location along the Baja California coast, the time to reach the estimated sizes at maturity is between 2.5 and $4.5 \mathrm{yr}$ while the time to reach the fishery at $159 \mathrm{~mm}$ is between 8 and $20 \mathrm{yr}$; growth rates at Santa Catalina Island yielded estimates of 8.5 to $9.0 \mathrm{yr}$ and 20 to $23 \mathrm{yr}$ for the times to reach maturity and the fishery, respectively (Tutschulte \& Connell 1988). The method used by Tutschulte (1976) of notching the shell of juveniles may further slow growth while the individuals repair the shell. Time to reach the MLSr for red abalone in northern California was $12 \mathrm{yr}$ (Rogers-Bennett et al. 2007). We suggest that our growth estimates may be conservative which are generally preferred for use in the evaluation of recovery strategies.

\section{Gender determination and size at maturity}

The size at maturity estimates based on sampling gonad tissue using the syringe method is a potential improvement over other non-lethal estimates because of greater accuracy. These results suggest the size at which $50 \%$ of the individuals were identifiable as a male or female was similar for both sexes (ca. $100 \mathrm{~mm}$ in length). However, until the correlation between gender determination by gonad sampling and maturity is verified, the estimates of size at maturity from this method should be used with caution. Further work with pink abalone could include an examination of the relationship between gender determination by gonad sampling and egg maturity.

\section{Survival estimation}

The survival of individuals larger than $79 \mathrm{~mm}$ in the Point Loma pink abalone population was estimated to be high $\left(0.77 \pm 0.05 \mathrm{yr}^{-1} \mathrm{SE}\right)$, which is consistent with adult survival estimates for other pink abalone populations at Santa Catalina Island, California $\left(0.82 \mathrm{yr}^{-1}\right.$; (Tutschulte 1976), and Baja California, Mexico (0.65 to $0.70 \mathrm{yr}^{-1}$; Doi et al. 1977, Marín Aceves 1981), reviewed in Shepherd \& Breen (1992). Annual variability in survival rates was not pronounced, nor did the data support separate survival rates for males and females in this population.

Damage to the foot of the abalone during the markrecapture process (i.e. bar cuts) negatively affected average survival for severely cut individuals relative to those individuals with little or no damage. Burge et al. (1975) and Tegner et al. (1989) suggested that bar cuts were responsible for sublegal mortality in the California abalone fisheries. Burge et al. (1975) also discussed the mortality due to an interaction of bar cuts and predation following replacement to the substrate. Today, however, the reduction in the numbers of large predators such as bat rays and sea otters in the Point Loma kelp forest may account for higher survivorship of slightly damaged abalone (Dayton et al. 1998).

\section{CONCLUSIONS}

Knowledge of vital rates for a population, and the inherent variability of those rates, is important for guiding recovery efforts in depleted populations. The construction of life-history-based population models can be critical tools used to inform restoration actions (Crouse et al. 1987, Gerber et al. 2004, Rogers-Bennett \& Leaf 2006). Slow-growing, long-lived marine animals may benefit from restoration actions which target improving adult survival and reproduction rather than enhancing juvenile survival via stocking (Gerber \& Heppell 2004). The results of the present study support the development of a species-specific population model for future evaluations of conservation efforts.

Recovery of pink abalone specifically will depend heavily on local reproductive success and oceanographic conditions which promote larval and juvenile survival. Successful reproduction will also require minimum viable population densities of adults in close proximity to enhance fertilization success, so that 
recruitment to the population can aid recovery. Our findings indicate that even if there has been widespread recruitment success immediately following the fishery closure in 1997, those individuals may only have reached a reproductive stage a few years ago and will not reach the historic commercial MLS until 2017. It will likely be much longer before additional recruitment to the population can begin to increase the spawning stock density. We caution that estimates of the time-to-recovery are contingent upon the continued fishery moratorium coupled with effective enforcement.

Acknowledgements. We thank P. Dayton for his enthusiastic support of this work and his dedication to studying California's kelp forests. This work was funded by California Sea Grant to L.R.B.; and to P. Dayton and P. Hastings, the University of California Marine Council Coastal Environmental Quality Initiative, the Edna B. Sussman Foundation, the Mia J. Tegner Memorial Fund, the Halliday Field Research Fund, and the California Department of Fish and Game. Special thanks to I. Taniguchi, and P. Haaker for their tireless enthusiasm for tagging abalone and the invaluable advice they gave early in the development of this project. This work would not have been possible without the additional help of many volunteer divers from Scripps Institution of Oceanography and the National Oceanic and Atmospheric Association white abalone lab at the Southwest Fisheries Science Center. Particular thanks to M. Kasuya, R. Todd, S. Mau, K. Riser, J. Schaeffer, J. MacDonald, and B. Pister for many years of help in the field. This is a contribution of the Bodega Marine Laboratory, University of California, Davis.

\section{LITERATURE CITED}

Akaike H (1974) A new look at the statistical model identification. IEEE Trans Automat Contr 19:716-723

Babcock R, Keesing J (1999) Fertilization biology of the abalone Haliotis laevigata: laboratory and field studies. Can J Fish Aquat Sci 56:1668-1678

Burge R, Shultz S, Oderrm M (1975) Draft report on recent abalone research in California with recommendations for management. Department of Fish and Game San Diego, CA

Caswell H (2001) Matrix population models: construction, analysis, and interpretation. Sinauer Associates, Sunderland, MA

Cormack RM (1964) Estimates of survival from the sighting of marked individuals. Biometrika 51:429-438

Crouse DT, Crowder LB, Caswell H (1987) A stage-based population model for loggerhead sea turtles and implications for conservation. Ecology 68:1412-1423

Dayton PK, Tegner MJ, Parnell PE, Edwards PB (1992) Temporal and spatial patterns of disturbance and recovery in a kelp forest community. Ecol Monogr 62:421-445

Dayton PK, Tegner MJ, Edwards PB, Riser KL (1998) Sliding baselines, ghosts, and reduced expectations in kelp forest communities. Ecol Appl 8:309-322

Doi T, Guzmán del Próo SA, Marín V, Ortiz M, Camacho J, Muñoz T (1977) Análisis de la población y diagnostic de la pesquería de abulón amarillo Haliotis corrugata en al area de Abreojos e Isla de Cedros B.C. Ser Cientifica Inst Nacional Pesca México 18:1-17
Gerber LR, Heppell SS (2004) The use of demographic sensitivity analysis in marine species conservation planning. Biol Conserv 120:121-128

Gerber LR, Tinker MT, Doak DF, Estes JA, Jessup DA (2004) Mortality sensitivity in life-stage simulation analysis: a case study of southern sea otters. Ecol Appl 14:1554-1565

Guzmán del Próo SA (1992) A review of the biology of abalone and its fishery in México. In: Shepherd SA, Tegner MJ, Guzmán del Próo SA (eds) Abalone of the world: biology, fisheries, and culture. Fishing News Books, Cambridge, MA, p 341-360

Haaker PL, Parker DO, Barsky KC, Chun CSY (1998) Growth of red abalone, Haliotis rufescens (Swainson), at Johnsons Lee, Santa Rosa Island, California. J Shellfish Res 17: $747-753$

Henderson KC, Parker DO, Haaker PL (1988) The survival and growth of transplanted adult pink abalone, Haliotis corrugata, at Santa Catalina Island. Calif Fish Game 74: 82-86

Jolly GM (1965) Explicit estimates from capture-recapture data with both dead and immigration-stochastic model. Biometrika 52:225-247

Krebs CJ (1999) Ecological methodology, 2nd edn. Benjamin/Cummings, Menlo Park, CA

> Lebreton JD, Burnham KP, Clobert J, Anderson DR (1992) Modeling survival and testing biological hypotheses using marked animals: a unified approach with case studies. Ecol Monogr 62:67-118

Marín Aceves V (1981) Parámetros poblacionales y diagnóstico de la pesquería de abulón amarillo (Haliotis corrugata) en Bahía Tortugas, B.C.S. Cienc Pesq 1:66-79

Morris WF, Doak D (2002) Quantitative conservation biology: theory and practice of population viability analysis. Sinauer Associates, Sunderland, MA

Rogers-Bennett L, Leaf RT (2006) Elasticity analyses of sizebased red and white abalone matrix models: management and conservation. Ecol Appl 16:213-224

Rogers-Bennett L, Rogers DW (2006) A semi-empirical growth estimation method for matrix models of endangered species. Ecol Model 195:237-246

Rogers-Bennett L, Haaker PL, Huff T, Dayton PK (2002) Estimating baseline abundances of abalone in California for restoration. Calif Coop Ocean Fish Invest Rep 43:97-111

Rogers-Bennett L, Allen BL, Davis GE (2004a) Measuring abalone (Haliotis spp.) recruitment in California to examine recruitment overfishing and recovery criteria. J Shellfish Res 23:1201-1207

Rogers-Bennett L, Dondanville RF, Kashiwada J (2004b) Size specific fecundity of red abalone (Haliotis rufescens): evidence for reproductive senescence? J Shellfish Res 23: $553-560$

Rogers-Bennett L, Rogers DW, Schultz SA (2007) Modeling growth and mortality of red abalone (Haliotis rufescens) in Northern California. J Shellfish Res 26:719-727

Seber GAF (1965) A note on the multiple-recapture census. Biometrika 52:249-259

Shepherd SA, Avalos-Borja M (1997) The shell microstructure and chronology of the abalone Haliotis corrugata. Molluscan Res 18:197-207

Shepherd SA, Breen PA (1992) Mortality in abalone: its estimation, variability, and causes. In: Shepherd SA, Tegner MJ, Guzmán del Próo SA (eds) Abalone of the world: biology, fisheries, and culture. Fishing News Books, Cambridge, MA, p 276-304

Tegner MJ, Breen PA, Lennert CE (1989) Population biology of red abalones Haliotis rufescens in southern California and management of the red and pink Haliotis corrugata 
abalone fisheries. Fish Bull 87:313-340

Tutschulte TC (1976) The comparative ecology of three sympatric abalones. PhD dissertation, University of California, San Diego, CA

Tutschulte TC, Connell JH (1988) Growth of three species of abalones Haliotis in southern California. Veliger 31: $204-213$

Editorial responsibility: Hans Heinrich Janssen, Oldendorf/Luhe, Germany
Vilchis LI, Tegner MJ, Moore JD, Friedman CS, Riser KL, Robbins TT, Dayton PK (2005) Ocean warming effects on growth, reproduction, and survivorship of Southern California abalone. Ecol Appl 15:469-480

White GC, Burnham KP (1999) Program MARK: survival estimation from populations of marked animals. Bird Study 46:120-138

Submitted: November 5, 2009; Accepted: February 21, 2011 Proofs received from author(s): May 9, 2011 